\title{
Artificial intelligence (Al) General Adoption Factors: A Systematic Review of the Literature
}

\author{
Debashish Roy \\ SP Jain School of Global management \\ 4855 Ariva Way , APT - 303 \\ San Diego , CA - 92123
}

\begin{abstract}
AI is rapidly changing the overall technology and business world by introducing basic automation tools to gamechanging solutions like a driverless car, Amazon Go etc. Tech companies are pioneers in adopting AI. Non-tech companies are also racing for AI adoption. Sometimes companies are facing wait or adopt syndrome because of a lack of information on the AI adoption status and where their peers are heading to. Also, companies that are planning or recently started their AI journey without an effective AI adoption strategy are facing significant roadblocks. There is minimal research done on finding AI adoption factors\& strategy in recent years.
\end{abstract}

The purpose of the study is to conduct a systematicliterature review for identifying important general AI adoption factors that can help the Technologyleaders to understand the current AI ecosystem \& build effective AI adoption strategies for their organizations.

\section{DEFINITION OF TERMS}

\section{ARTIFICIAL INTELLIGENCE}

Artificial intelligence (AI), is also sometimes known as machine intelligence. It is a form of intelligence that is demonstrated by machines. It is in contrast to the natural intelligence that is portrayed by humanbeings and some animals. In the area of computer science, AI research refers to the study that is related to intelligent agents. They are the devices that can perceive their environmental setting and further take action to maximize the chance of accomplishing the intended goals. In other words, AI is the technology where a machine can mimic the "cognitive" functions that are demonstrated by human beings, like problem-solving and learning.

\section{TECHNOLOGY ADOPTION}

It is a process thatbegins with the awareness of a specifictype of technology and ultimately progresses through diverse stages. It ends when technology is either adopted or rejected.

Strategy: It refers to a plan or a method selected to bring about an intended future,like accomplishing a goal or finding a solution to anissue.

\section{Keywords}

Artificial intelligence, Technology Adoption, Strategy

\section{INTRODUCTION}

Artificial intelligence (AI) is the most significant opportunity for companies, industries \& nations to transform themselves rapidly and emerge as a leader during the fourth industrial revolution. AI has already started impacting human lives at a phenomenal speed. Organizations that are slow to adopt AI technology can face the threat of extinction in the coming years because AI will likely to upend various industries soon. Industry leaders recognize the importance of adopting AI quickly to be competitive and relevant in the new world. Still, enterprises are facing some significant challenges in AI adoption, which include but not limited to skill shortage, culture shock, adopt or wait dilemma, colossal investment, ethical issues, etc. Today's most profitable and successful technology companies have adopted AI rapidly. Still, it's anobstacle for non-tech firms to adopt Artificial Intelligence because of lacking in an effective AI adoption strategy. Some companies are waiting for the technology to be matured, which can result in costly mistakes in the future. Therefore, our research's objective is to recognize the key factors influencing the adoption of AI technology. These strategies can help non-tech and other organizations to adopt AI technology swiftly and lower the risk of extinction in the upcoming epic industrial disruption [29].

Artificial Intelligence (AI) is a repeated buzz word in the modern setting, which is highlighted in news and events relating to the digital space.In the coming years,it could be the cause of massive job losses. This technology could give rise to the era when finally,computer systems could take over, just like predictions have been made in science fiction movies like Star Wars [30]. In the past few years, AI has gone from perennial vapourware to a major technological approach that can give technology a transformational makeover. Computer systems have now learned to identify faces as well as objects, comprehend the verbal word, and interpret many languages [35]. The term"Artificial Intelligence" or AIfirst was used in the year 1956, but in recent years the technology has become available to many because of advancements in hardware and software solutions. AI technology is an apt example of exponential technology. In the future, it is expected that there will be a significant change in computer performance, as has been observed via Moore's Law [39]. Currently, AI,as well as data science, have complemented the understanding and the utilization of complex data to get insights that assist in the decision-making process. Realizing such a potential, organizations are prioritizing $\mathrm{AI}$ as an area that can be expanded further [36]. It is necessary to focus on AI in the business backdrop as it has the potential to revolutionize entire industries in the coming decade [34]. But, the promise of AI will be fulfilled only by establishing a clear, coherent link between AI and business value [32].

CIOs are finding it challengingto deploy AI. Only one in 25 says their organization has deployed AI, according to Gartner's 2018 CIO Survey. However, one-fifth claim to be trying to experiment with the technology or to establish shortterm plans for it, and one-quarter say that $\mathrm{AI}$ is among their mid- or long-term plans [32].

There are major challenges in adopting Artificial Intelligence for businesses. Machine Learning and AI are not turnkey 
solutionsuntil now.Thusadopting AI into business needs a specific set of skills as well as resources [34]. Without a welldefined and effective strategic planrelating to AI, firms face the risk of wasting financial resources, falling short in terms of performance, and falling behind their rivals [32].

Various leaders believe that $\mathrm{AI}$,as well as cognitive technologies, are highly disruptive technologies forces of the 21 st century. But majority firms do not have a suitable strategic approach to deal with such technologies $[17,26]$

Therefore, every organization should invest in building a robust technology adoption strategy for AI. These can help to mitigate the risk \& ensure the effective implementation of AI technologies in the organization. But there is very little research has done on exploring the effective AI technology adoption strategies \& status in recent years. This inadequacy heightened the need for this kind of study to explore technology adoption status \& strategies for AI used by AI Technology Managers [11].

\section{SYSTEMATIC LITERATURE REVIEW METHODOLOGY}

A literature review refers to a critical summary of published research articles in a specific area or topic. This helps to identify the existing researches, gaps \& potential future research areas in that topic. During our initial literature search, there are found very few relevant published research articles in peer-reviewed journals in the areas of AI status \& strategies. Also, we noticed. Some grey literature is available related to my research questions in the form of industry reports, white papers from consulting \&technology companies. For further review, they have chosen to carry out a systematic review of the literatureaccording to the guidelines [2]. The guidance provided by is highly relevant for conducting SLR in the information systems domain and followed by many researchers [2].

One such SLR was conducted by in the software quality domain using a similar method [1].

To find more relevant researches in these areas, it has been decided to conduct a detailed SLR by following proper SLR processes. It has been prepared a thorough SLR process (See Figure 1), which is inspired by the work of Ghanbari, Vartiainen, \&Siponen. By considering the limited published research, they have also included a review of grey literature in my SLR process [1].

The following sections will cover the SLR process in detail.

\subsection{Initial Literature Review Study (Stage 0)}

They have adopted the SLR strategy introduced in the work in the software quality domain [1]. To identify the primary keywords, a preliminary literature review was performed. They couldn't identify a considerable number of literature during our initialsearch, but it helped in identifying relevant keywords that we used in the subsequent phases. 


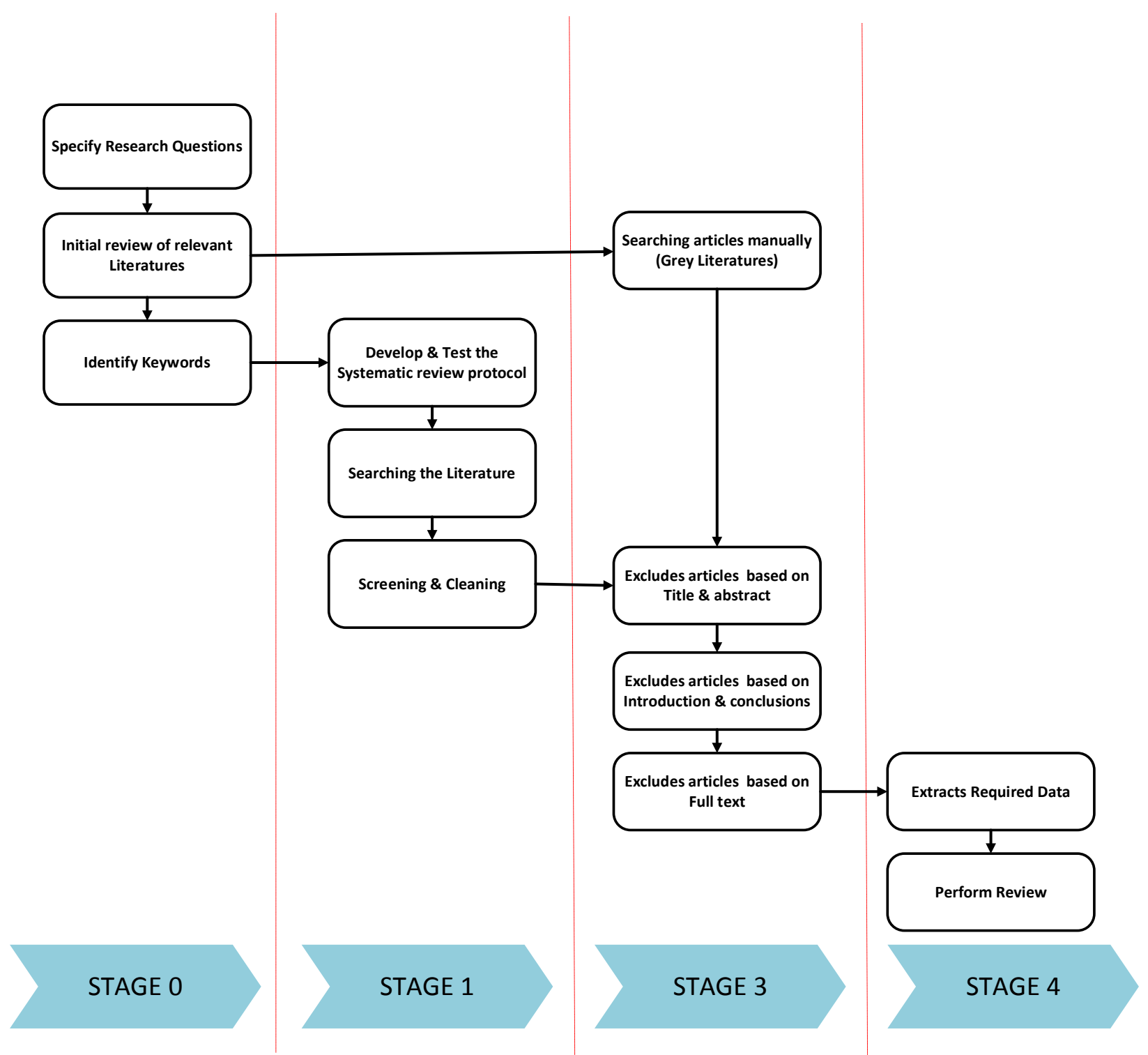

Fig 1: SLR Process

\subsection{Planning the Review (Stage 1)}

\subsubsection{Research Questions}

The most important step in a systematic literature review protocol is to formulate an appropriate research question (RQ). In this SLR, it will focus on the below research questions.

RQ1: What are the factors influencing AI Technology Adoption?
The first step in the SLR process is to the retrieval of articles from the selected databases, which is called primary selection; in this review, databases used to search the articles listed in Table 1. Initial Database search may return large numbers of articles, and during secondary selection, a screening method can be employed to find the relevant articles.

Post-secondary screening core information will be extracted from the articles based on a predefined template for further analysis.

\subsubsection{Search Strategy}

Table 1: The selected databases used for the SLR search stage

\begin{tabular}{|l|l|l|}
\hline Database & Link & Type \\
\hline Business Source Complete & https://www.ebsco.com & Digital Library \\
\hline ProQuest & https://www.proquest.com/ & Digital Library \\
\hline Manual search & $\begin{array}{l}\text { https://scholar.google.com/ } \\
\text { https://www.google.com/ }\end{array}$ & Search Engine \\
\hline
\end{tabular}




\subsubsection{Search Terms}

The "search terms" were identified by using appropriate keywords from the research questions as well as the outcome of the initial literature review process. By unifying the search keywords, the search strings have been developed, as shown in Table 2 .

Table 2: Search terms identified as per research questions

\begin{tabular}{|l|l|}
\hline Primary Search terms & Artificial intelligence \\
\hline Secondary Search terms & $\begin{array}{l}\text { Status, adoption Strategy, Technology Adoption, Adoption } \\
\text { challenge }\end{array}$ \\
\hline Search String & $\begin{array}{l}\text { (artificial intelligence) AND ((adoption strategy) OR } \\
\text { (technology adoption status) OR (adoption challenge)) }\end{array}$ \\
\hline Additional filters & $\begin{array}{l}\text { Date Range: } 2008 \text {-2019 } \\
\text { Language: English } \\
\text { Full-text Articles } \\
\text { Search Strings presents in Title or Abstract }\end{array}$ \\
\hline
\end{tabular}

To identify the relevant articles, it has been searched in Business source complete,ProQuest, google scholar,and google during Feb2019. Table 3 contains the search results as conducted during Feb 2019.

Table 3: Search results (February 2019)

\begin{tabular}{|l|l|l|l|}
\hline Database & Total Number & Peer-Reviewed & Date Range \\
\hline ProQuest & 819 & 67 & $2008-2019$ \\
\hline Business Source Complete & 6 & 1 & $2008-2019$ \\
\hline Manual search & 187 & 70 & $2015-2019$ \\
\hline
\end{tabular}

\subsubsection{Selection Criteria and approach}

In the review, each article was evaluated based onpredefined exclusion and inclusion criteria. Articles were regarded relevant for our study if it provides information related to AI adoption status, strategy, factors or challenges. It excluded the articles from their study if it was not published in English. It also followed a 3-step process for evaluation, as discussed further.

\subsubsection{Conducting the Critical Review (Stage 2)}

In the 1st round of stage twoit has been evaluated every study by going through the title as well as the abstract.

Table 4: Articles Selected Through Three Rounds of Evaluations

\begin{tabular}{|l|l|l|l|}
\hline Round & $\begin{array}{l}\text { Numbers of } \\
\text { Articles }\end{array}$ & Excluded Article & Evaluated Based on \\
\hline $1^{\text {st }}$ & 1012 & 905 & Title and abstract \\
\hline $2^{\text {nd }}$ & 107 & 55 & Introduction and conclusion \\
\hline $3^{\text {rd }}$ & 52 & 4 & Full Article \\
\hline
\end{tabular}

During the 2nd round of stage 2, it has been evaluated all 107 articles based ontitle, abstract, introduction as well as the conclusion sections. Ultimately at this stage,52 articles in total were chosen for further analysis. During the final evaluation round, the complete texts of these articles were analyzed based on the selectedcriteria. As an outcome of this review process, a total of 48 articles were considered as relevant for our studies (see table 3 ).

All three phases, our main criteria were to identify if the

Table 5: Data items extracted from the articles

\begin{tabular}{|l|l|l|}
\hline ID & Data Item Extracted & Data Item description \\
\hline DI1 & Title of Articles & The title of the article \\
\hline DI2 & List of Authors & The full list of authors of the Article \\
\hline DI3 & Year of Publication & The year in which the article was published \\
\hline DI4 & Summary & A summary of the article \\
\hline DI5 & Major findings & Major findings in bullet points \\
\hline DI6 & Factors & Factors associated with AI Adoption \\
\hline DI7 & Future Scope & Future scope of research \\
\hline
\end{tabular}




\section{RESULTS OF THE LITERATURE REVIEW}

The section highlights the results from the SLR. As described in the previous sections, the initial sample encompassed 1012 articles, out of which 38 articles were selected via three rounds of the selection process (refer appendix A). These include published articles in peer-reviewed journals, and proceedings from conferencesas well as workshops between 2010 and 2020. It has been also included a few grey kinds of literature in their review process to broaden their search horizon and also to consider the limited research on this topic. Gray literature also provides data thatis typically not found within commercially published literature. Gray literature might minimize bias relating to the publication, expand the comprehensiveness and timeliness of the reviews, and present a balanced picture relating to the available evidence [3]. After extracting all the relevant data items from the selected articles, we used that information to address the research questionsbelow.

\subsection{RQ1: What are the Factors Influencing AI Technology Adoption?}

Based on the detailed literature review, various issues, obstacles, and strategies were found related to AI technology adoption. Often systematic review can be complicated and hard to conduct, and visual text mining (VTM) can aid in the systematic review process [4]). The "visual text mining" model was used for better comprehension of the keywords in the articles that have been referred to.

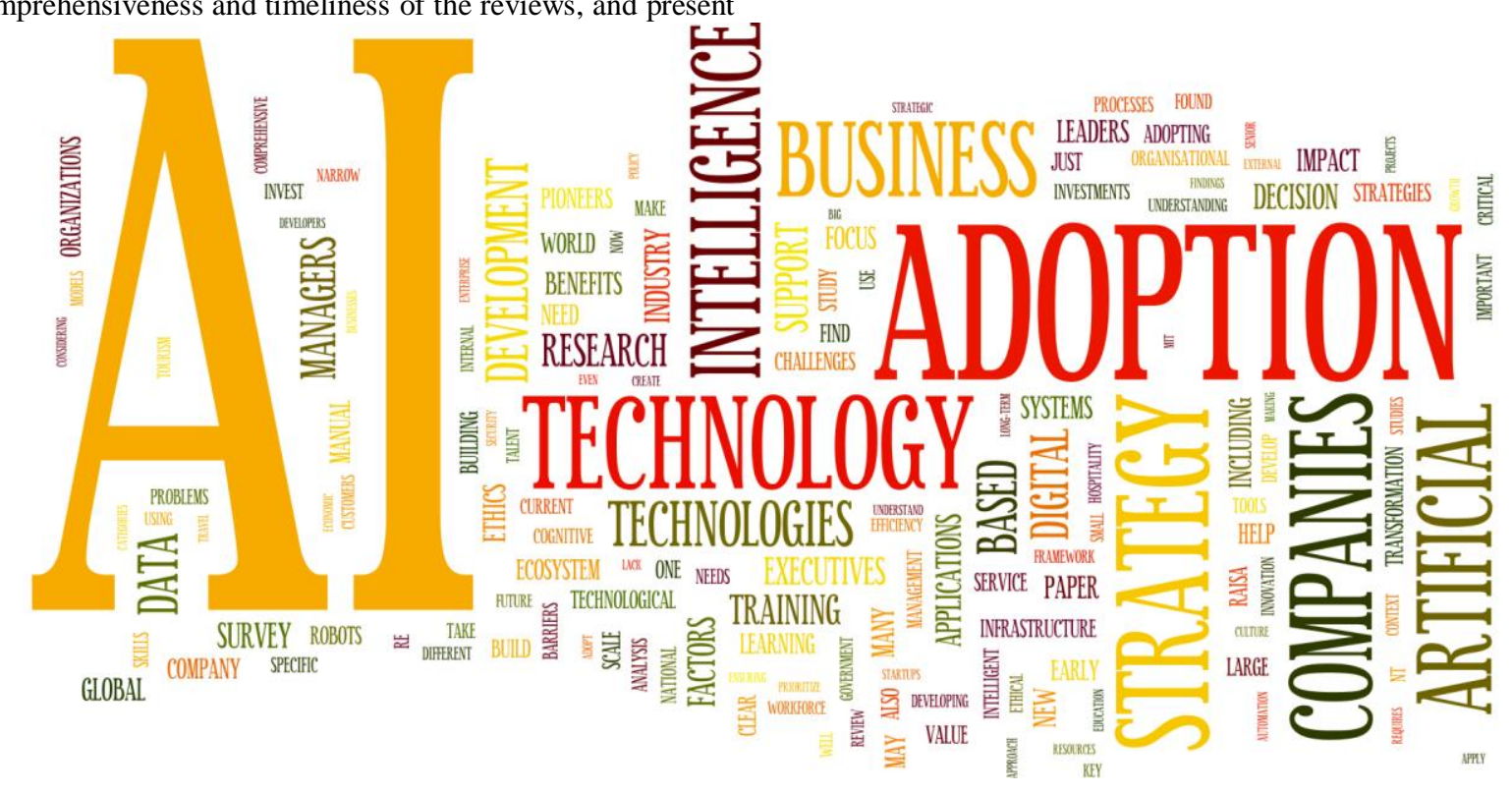

Fig 2: Word cloud view of the title,abstract,summary, and conclusions

\subsubsection{Technology and Business Collaboration}

Collaboration between technology and business came out as one of the most critical factors for successful AI technology adoption. While the impact of AI on business is a major issue for most companies, executives also faceadditional challenges related totheir market and competitive position under diverse AI adoption scenarios [9]. Mapping the various AI categories with specific business functions is crucial before starting the AI journey. Also, creating baseline adoption curves for each AI category and applying amendments relating to the adoption curves on the basis of the internal as well as the external forces as organizations progress through their AI journey is vital for long term success. Also, highlighted that embarking on an AI Journey is not enough for success rather than chasing rainbows inside the hype cycle; savvy companies need to grab the opportunity to start on a realistic and smart adoption strategy instead [13]. An excellent example of a narrow $\mathrm{AI}$ in action can be seen at Liberty Mutual, one of the world's largest global insurance firms. It now advertises the ability to complete an auto-insurance quote within 10 minutes on its website [21].

$51 \%$ of Artificial Intelligence leaders have predicted that by the year 2020, the AI technology will have the most significant internal impact on the back-office operations functions of finance or accounting and IT. Various leaders predict it, and experts that AI can transform enterprises. However, little has been discussed on how firms can utilize such next-generation technologies. Thus the first step is to identify and analyzing the prevailing business problems. It can help to understand the adoption possibilities and how proper collaboration between business and technology can make it possible [13]. So, in a nutshell, adopting the AI technology requires a combination of Business and IT strategy [22].

The Global Executive Study and Research Report of the year 2018 by MIT Sloan Management Review showed that early Innovator firms are hauling ahead of their rivals by making commitment to AI technology and emphasizing on revenuegenerating applications instead of focusing on cost savings. Such early implementers are positioning themselves ahead to take advantage of AI at scale [15]. To choose the compelling use cases, the involvement of executives, managers from all levels across technology and line of businesses are needed [25]. Engaging only tech leaders to drive transformation programs may fail. Strong collaboration between technology, data and business teams are much needed for success [28].

\subsubsection{AI Leadership}

A knowledgeable and empowered leader can speedup AI adoption for organizations. The adoption of AI needs 
adaptability.Executives must help the managers to adjust to new and intelligent technologies. They must involve managers from varying work levels as well as geographies in the initial experimentation stage while implementing AI in the work setting. Such kind of involvement will enable them to get acquainted with the requisite skills and potential solutions that are driven by $\mathrm{AI}$ as well as human input [25].

In the technology-driven era, a strategic approach towards digitalization might not be suitable. Establishing a digital strategy would mean that the organization is not focusing on the true value of digital transformation. There is a need for a better strategy that is enabled by digital. In diverse industries starting from hospitality to chainsaw manufacturing, great leaders are responsible for transforming their business by using technology. Thusbuild suitable leadership capabilities is necessary to adopt AI technology [27].

\subsubsection{AI Education}

People enablement in future technologies will happen through long-term training, and it can enable the employees to see AI as an enabler rather than a threat. Employees need to upskill in higher-value work from a different line of business [8].

Business leaders must be aware of the basics of AI technology, and they must deploy teams with suitable skills and expertise to handle AI projects [12]. They can establish a central technology capability to help in developing the right skill sets within the company [14].

Also, a high focus on training is required at each level,starting from college degree programs to very professional trainers as firms must develop deep learning skills in their professional staff [23].

\subsubsection{Start-Up Mindset}

It is necessary to have a start-up mindset and zeal to explore new things, but the envelope must not be pushed too far and too fast. Before emphasizing on autonomous cars and fully robotized call centers, firms can introduce other changes by making data-informed decisions, focusing on mobile collaboration, and employing ERP to transform the business processes (Westerman, G.,2018).

Judicious Chief Information Officers must focus on an adoption strategy that enables them to introduce and test the latest technologies without locking the business into any longterm commitment [8].

\subsubsection{AI Technology Infrastructure}

Pioneers have committed themselves to AI, and they are looking forward to scalingthe AI technology throughout their business entities [15]. As companies move from the experimental stage to real enterprise-level adoption of AI technologies, it will require a substantial amount of computing resources as well as an ecosystem in place.

Cloud services are also essential for AI adoption. It will make sure that the core requirements of firms, as well as workloads, match technology to the demands needed to sustain AI. It can also ensure that this objective is achieved at a suitable cost level [23].

\subsubsection{AI Talent}

Developing AI Talent is very crucial for the effective adoption of AI technology. Thusthe need to invest in cultivating AI talent is essential. Individual firms could benefit by attracting the most productive AI talent from universities, but the entire ecosystem of AI innovation might be at the receiving end [10]. Access to AI-based skills for the organization is much needed for starting their adoption journey, and the battle for AI talent may become much intense as more companies launch their adoption journey [22]. To address the shortage of AI-trained engineers and developers, in-house or external AI training programs need to be conducted [23].

\subsubsection{AI Research and Development}

AI technology can solve varying critical societal problems, and it can become a decisive factor for the entire economy [19]. Companies are starting to adopt the AI technology in their business, but still, various questions must be answered. AI technology is still in its nascent stage, and further research and development are needed to make progress in the area [10].

\subsubsection{Data Architecture Supporting AI}

Data related challenges are prevalent and important barriers to AI adoption. Building a powerful functional predictive model needs a considerable volume of quality data. So companies need to develop a robust data architecture supporting AIbased technology [22]

AI initiatives need a humongous amount of well- defined data, so firms must not run headfirst into such projects, as per experts. They must instead follow a measured method that recognizes the issues that $\mathrm{AI}$ can overcome, and account for prerequisites such as well-organized data and a skilled team to handle AI projects [12].

\subsubsection{AI Ecosystem}

To succeed in AI adoption, companies need to do more than just make investments. The new technology requires a proper ecosystem, solid AI inputs such as skill set, additional research work, data and information,and entities that are free and motivated to utilize AI. Support from the federal government is also necessary to develop a proper AI ecosystem [10].

The adoption of AI requires suitable infrastructure development, appropriate policy and regulations, human resource development, and research and development. The key stakeholders must work cohesively to discuss critical aspects relating to Artificial Intelligence. The government also plays a critical role in developing the infrastructure, design applications in the public sector, create policies and regulations, human resource development, and technology development. Adequate support from the industry and the establishment of a healthy ecosystem is required for successfully adopting AI [24].

A suitable AI ecosystem has robust networks between science, economic actors, and society. Innovation can be boosted by establishing collaboration and proper exchange between researchers, developers, companies, universities, start-ups, and investors. For promoting such an ecosystem, various political measures at different levels have must be taken to create a wider and comprehensive strategy [19]

\subsubsection{AI Policy}

AI policiesat the national level are necessary to boost competition, improve national security, and magnify the societal benefits that a nation can get from it. The policy should foster innovation-friendly regulation $[10,33]$.

\subsubsection{AI Platforms}

Build vs. buy AI capabilities is a crucial decision foran 
organization that needs to be made to spearhead their AI adoption journey.

Building AI capabilities are suitable for firms that need AI technology to power their core business processes and ensure strategic success. Uber and other driverless vehicles, or Netflix's innovative recommendation engine, have followed this approach. But for improving non-core activities of business like human resources, finance, and accounting or customer service, an ideal option is to buy a well-tested, offthe-shelf AI product [17].

Buying of AI capability can give rise to numerous benefits. For example, the suppliers take responsibility for tricky issues relating to the integration of new AI applications into the existing IT environment and providing training to employees to use AI technology. Moreover, they offer specialized algorithms regarding tasks such as image recognition, which requires feeding thousands of images into a program for teaching it to identify objects. According to Davenport, it is a cheaper alternative as compared to spending millions of dollars on hiring data scientists to develop internal AI capabilities [16, 26].

\subsubsection{AI Ethics}

AI algorithms could respond unpredictablyto new inputs, which can create significant issues when we put an AI agent in charge of critical systems. It's challenging to make predictions of the behavior of an AI system. AI put in charge of critical systems may produce unforeseen harmful side effects. The current technology is far away from AGI, and current research should not be restrictedas it can bring many benefits in diverse fields [20,43]. Embedding ethical aspects in AI applications are critical to avoid impact on the brand image.

\section{LITERATURE REVIEW SYNTHESIS}

The twelve varying factors illustrated in Table 6 helped to understand the elements that influence the adoption of artificial intelligence (see Figure 3). It has been tried to map all these factors in the aspects of environmental, technological, and organizational contexts based on the TOE framework. The "technology-organization-environment" (TOE) framework is highlighted [5]. The Processes of Technological Innovation (1990)which has described the entire innovation process starting from the development and designing of innovation by engineers to the implementation of these innovations by the end-users of a business [18].

The TOE framework does not focus on a series of factors that affect the adoption of innovation, unlike other adoption models [6]. So, the categorization of the elements was done based on the experience as well as practice from a similar research area.

Table 6: Primary Studies Were Selected Through Three Rounds of Evaluations

\begin{tabular}{|c|c|}
\hline Identified Factors & Instances \\
\hline AIEducation/Competency Development & $\begin{array}{l}\text { Prioritize long-term training (AT1), AI Education (AT5, AT7, AT9, AT19), } \\
\text { Building AI Competency (AT10), Training staff (AT12, AT16, AT17) ) in-house } \\
\text { or external AI training program(AT14) }\end{array}$ \\
\hline Technology \& Business Collaboration & $\begin{array}{l}\text { Define AI taxonomy and AI categories (AT2), Establish baseline adoption curves } \\
\text { (AT2), Explore the intersection of AI categories with specific business functions } \\
\text { (AT2,AT6,AT8, AT11,AT16), Recognize the advantages and the limitations } \\
\text { (AT4), Find the applications where narrow AI can make meaningful } \\
\text { contributions to accuracy and efficiency (AT4,AT6,AT8), Start exploring AI now } \\
\text { - together (AT16), Domain knowledge into AI system (AT17), Collaboration } \\
\text { between business and IT (AT18), connect technology, data and business teams } \\
\text { (AT19) }\end{array}$ \\
\hline Data Architecture supporting AI & $\begin{array}{l}\text { Ensuring Data Availability (AT3, AT14), large volumes of well-organized data, } \\
\text { Sustainable data infrastructure (AT10), Data Architecture (AT13) }\end{array}$ \\
\hline AI Talent & $\begin{array}{l}\text { Developing AI Talent (AT3, AT17), Build In-house AI Expertise (AT5, AT6), } \\
\text { Develop AI Skill (AT13), shortage of AI-trained engineers and developers } \\
\text { (AT14), Recruiting AI talent (AT16) }\end{array}$ \\
\hline AI Ethics & $\begin{array}{l}\text { AI is creating both fears and hopes among workers (AT8), Ethical AI ( AT10, } \\
\text { AT11, AT12, AT16), Governance\& AI accountability (AT13) }\end{array}$ \\
\hline AI Technology Infrastructure & $\begin{array}{l}\text { Building Processes and Platforms for AI at Scale (AT8), Infrastructure } \\
\text { requirements for AI (AT10, AT14), cloud services are essential to the AI } \\
\text { application (AT14), technological and infrastructure barriers (AT19) }\end{array}$ \\
\hline AI Research \& Development & $\begin{array}{l}\text { AI Research \& development (AT10, AT3), Attract the best researchers and } \\
\text { developers (AT10) }\end{array}$ \\
\hline AI Ecosystem & $\begin{array}{l}\text { Develop partnerships (AT1), Competitor and Industry Analysis (AT6), AI } \\
\text { Ecosystem (AT15) }\end{array}$ \\
\hline Start-up Mindset & $\begin{array}{l}\text { Focus on start-ups (AT1), Identifying and Analyzing Current Business Problems } \\
\text { (AT6), Starts from Basic (AT6), Start-up mode (start from small) (AT18) }\end{array}$ \\
\hline AI Leadership & $\begin{array}{l}\text { AI-focused Leadership Development (AT7, AT 18), Empower a leader (AT7),the } \\
\text { involvement of executive/managers from All Levels (AT16) }\end{array}$ \\
\hline AI Policy & Foster innovation-friendly regulation (AT3, AT15), Company Culture (AT12) \\
\hline AI Platforms & $\begin{array}{l}\text { Invest in an AI platform (AT1), Central technology capability, platform or } \\
\text { repository(AT7), Building Processes and Platforms for AI at Scale (AT8) }\end{array}$ \\
\hline
\end{tabular}




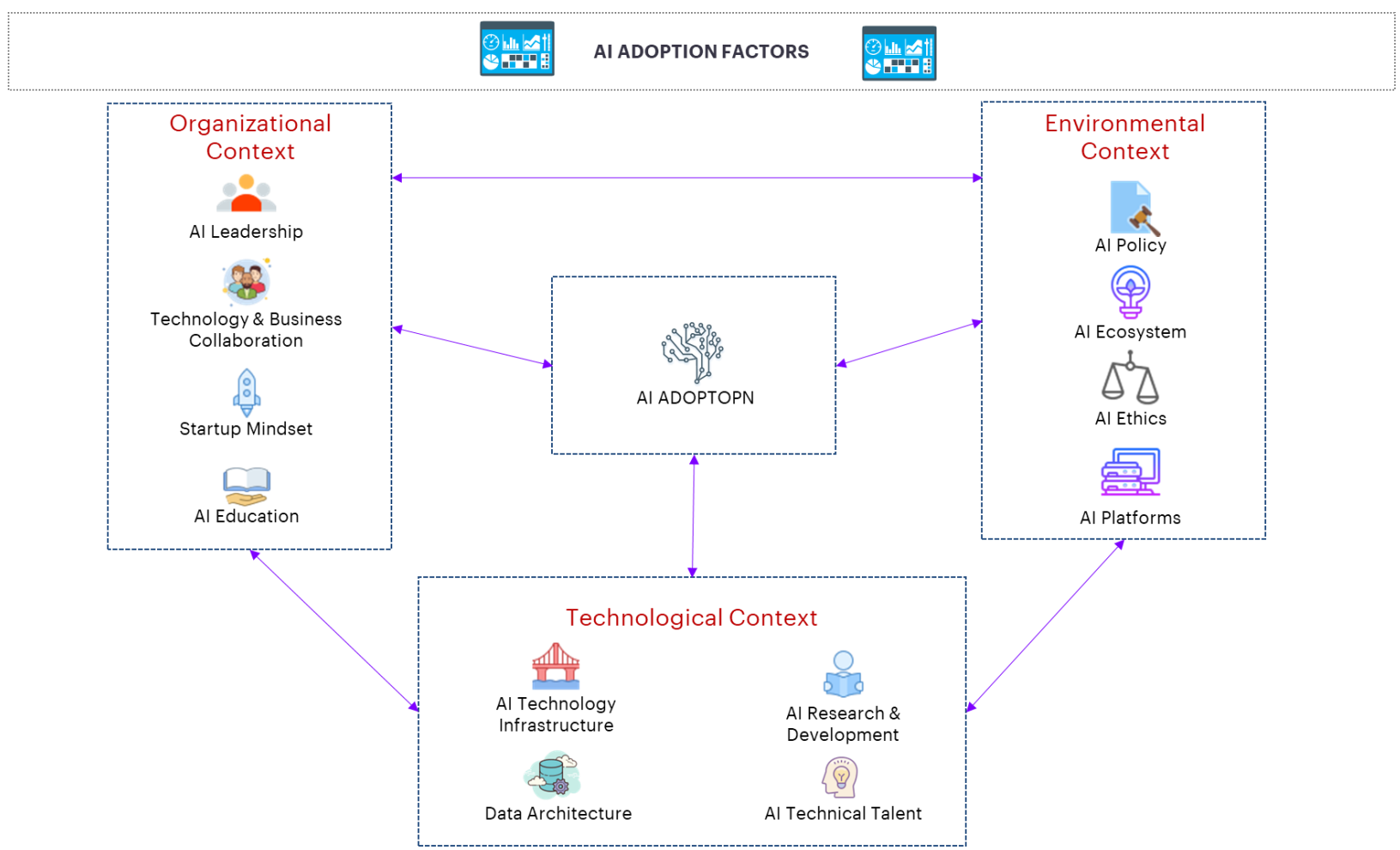

Fig 3: A research framework for AI adoption Status (Adapted from the TOE framework)

\subsection{Technological Setting}

Technological readiness in Figure 3 means how a business is prepared to adopt and integrate AI.

Based on our analysis, AI Adoption is highly influenced by the technological context,

Four main factors that influence that falls under this area are AI technology infrastructure, Data Architecture, AI research and development, and technology talent equipped with AI skill. These technological factors play a vital role and influence $\mathrm{AI}$ adoption.

Organizations need to consider the challenges and concerns of adopting new technology cautiously. So technological readiness is vital as it provides a better way to identify the advantages of such a technical implementation.

\subsection{Organizational Setting}

Organizational contextinvolves the attributes as well as the resources of a company [7]. Four vital organizational factors, including AI Leadership, AI education, technology, and business collaboration and start-up mindset, were identified as they help in Artificial Intelligence adoption.

Collaboration between technology and the business team can set up the perfect foundation to start the AI adoption journey by bringing compelling uses cases on the table.

The availability of proper AI training courses and start-up mindset also has a favorable impact on the overall application or adoption curve.

\subsection{The Environmental Setting}

The environmental setting encompasses the overall structure of the industry, the absenceor the presence of technology service providers, as well as the regulatory context [7].
During our literature review, it has been found four important factors (AI Policy, AI Ecosystem, AI Ethics, and AI Platforms) which are relevant from the environmental context.

AI adoption involves the development of infrastructure, the policy as well as regulations, research and development, and the availability of AI platform solutions. All stakeholders must cohesively discuss these issues. The government can play a chief role in developing suitable infrastructure, work on applications in the public sector, the policy as well as regulations, development of technology,and Human Resource Development. However, support from the industry is necessary to overcome these obstacles.

The key characteristics of a functional AI ecosystem include the existence of strong networks between science, the presence of economic actors (both big firms and start-ups), and the entire society.

Innovation can take place only when there are collaboration and dialogue between participants like developers, researchers, investors, universities, firms, and start-ups. Diverse political measures on different levels are required to promote such an ecosystem to create a broader and integrated strategy.

\subsection{Future Scope for Research}

In the research, 12 critical factors have been identified from the current literature, which are important for AI technology adoption. But how these factors will impact the adoption is not known. Therefore, further research is needed to assess the importance of various factors in terms of AI adoption. A detailed survey can be conducted to find out the importance of various factors associated with AI adoption. In the following table, there has been providedseveral important future possible research areas we have identified during our study. 


\begin{tabular}{|c|c|c|c|}
\hline ID & Future Research areas & Year & Author(s) \\
\hline AT10 & $\begin{array}{l}\text { Societal fears about the effects of AI on the labor market impacting AI } \\
\text { Adoption }\end{array}$ & 2018 & $\begin{array}{l}\text { Harhoff, D., Heumann, S., } \\
\text { Jentzsch, N., \& Lorenz, P. }\end{array}$ \\
\hline AT10 & Can involving citizens in the AI ecosystem help in AI adoption? & 2018 & $\begin{array}{l}\text { Harhoff, D., Heumann, S., } \\
\text { Jentzsch, N., \& Lorenz, P. }\end{array}$ \\
\hline AT10 & $\begin{array}{l}\text { Impact of building the legal requirements and ethical principles directly into the } \\
\text { AIcode. }\end{array}$ & 2018 & $\begin{array}{l}\text { Harhoff, D., Heumann, S., } \\
\text { Jentzsch, N., \& Lorenz, P. }\end{array}$ \\
\hline AT11 & $\begin{array}{l}\text { Can minimizing ethical issues of AI by not using AI in critical systems or the } \\
\text { decision-making process help in AI adoption? }\end{array}$ & 2016 & Barnes, E \\
\hline AT12 & Relationship between People's perception and AI adoption & 2017 & Ivanov, S. H., \& Webster, C. \\
\hline AT12 & Increase Employee acceptance of AI tech impacting overall adoption & 2017 & Ivanov, S. H., \& Webster, C. \\
\hline AT12 & Corporate culture impact on AI adoption & 2017 & Ivanov, S. H., \& Webster, C. \\
\hline AT13 & $\begin{array}{l}\text { proper assimilation of AI-based technology, post the organizational adoption } \\
\text { decision. }\end{array}$ & 2017 & Rao, T \\
\hline AT14 & $\begin{array}{l}\text { Understanding the pre and post-adoption parity in the factors considered to } \\
\text { bepart of the adoption decision, i.e., expected benefits vs. actual benefits } \\
\text { accruedpost adoption. }\end{array}$ & 2018 & O'reilly \\
\hline AT10 & $\begin{array}{l}\text { Developing AI skills at every level, starting from a college degree program, is } \\
\text { essential to increase AI Adoption? }\end{array}$ & 2018 & $\begin{array}{l}\text { Harhoff, D., Heumann, S., } \\
\text { Jentzsch, N., \& Lorenz, P. }\end{array}$ \\
\hline AT8 & What are the implications of AI in the future of work? & 2018 & $\begin{array}{l}\text { Ransbotham, Gerbert, Reeves, } \\
\text { David, \&Spira }\end{array}$ \\
\hline AT8 & How will AI affect economic growth? & 2018 & $\begin{array}{l}\text { Ransbotham, Gerbert, Reeves, } \\
\text { David, \&Spira }\end{array}$ \\
\hline
\end{tabular}

\section{CONCLUSION}

In the technology-driven times of the 21 st century, AI technology is a powerful innovation that can revolutionize how human beings deploy the technology. Even though the technology is in its nascent stage, it has the potential to boost automation to a significant degree. The systematic literature review that has been presented sheds light on how the AI technology has evolved with the passage of time and how it can give an edge to AI managers.

In the highly competitive and dynamic organizational setting, the effective use of the AI technology can give an edge to business concerns irrespective of the industry in which they function. The new branch of technology has given rise to a unique and new opportunity that can enable businesses to progress further by automating their business processes and functions. AI can be integrated into business strategy, and such an approach can help firms to carry out the business processes efficiently and effectively.

A diverse range of factors has been identified in the review that influences AI adoption in the business backdrop. The key factors are a collaboration between technology and business, presence of empowered and knowledgeable leaders, education on Artificial Intelligence, start-up mindset, infrastructure to support AI technology, AI talent, Research and Development relating to Artificial Intelligence, Data Architecture that supports AI, suitable AI ecosystem, policies, platforms, and ethical aspects relating to the AI technology. Thus, even though the application of Artificial Intelligence technology can give a competitive advantage to organizations, it is necessary to take into account various elements that can mold the successful integration of innovative technology. The study has highlighted that these are some of the key areas of consideration that can impact the adoption of $\mathrm{AI}$ in organizations. Further research is needed to understand the actual importance of theses factor in AI adoption under various contexts.

\section{REFERENCES}

[1] Ghanbari, H., Vartiainen, T., \&Siponen, M. (2018). Omission of Quality Software Development Practices: A
Systematic Literature Review. ACM Computing Surveys, 51(2), 38:1-27. https://doi.org/10.1145/3177746

[2] Okoli, C., Schabram, K. (2010). "A Guide to Conducting a Systematic Literature Review of Information Systems Research," . Sprouts: Working Papers on Information Systems, 10(26). http://sprouts.aisnet.org/10-26

[3] Paez, A. (2017). Grey literature: An important resource in systematic reviews. Journal of Evidence-Based Medicine. https://doi.org/10.1111/jebm.12265

[4] Malheiros, V., Hohn, E., Pinho, R., Mendonca, M., \& Maldonado, J. C. (2007). A Visual Text Mining approach for Systematic Reviews. First International Symposium on Empirical Software Engineering and Measurement (ESEM 2007), 245-254. https://doi.org/10.1109/ESEM.2007.21

[5] Tornatzky, L. G., \& Fleischer, M. (1990). The processes of technological innovation. Lexington, MA: Lexington Books. Journal of Management Information Systems, 15(4), 187-214.

[6] Aboelmaged, M. G. 2014. "Predicting E-Readiness at Firm-Level: An Analysis of Technological, Organizational and Environmental (TOE) Effects on EMaintenance Readiness in

[7] Baker, J. (2012). The Technology-OrganizationEnvironment Framework. In Y. K. Dwivedi, M. R. Wade, \& S. L. Schneberger (Eds.), Information Systems Theory (Vol. 28, pp. 231-245). Springer New York. https://doi.org/10.1007/978-1-4419-6108-2_12

[8] Rahnama, H. (2017). 3 Ways to Create a Strategic Framework for AI Adoption. Retrieved January 3, 2019, from https://www.informationweek.com/big-data/3ways-to-create-a-strategic-framework-for-aiadoption/a/d-id/1329697

[9] Evans, N. D. (2018, April 17). Navigating artificial intelligence strategy in your industry. Retrieved January 4, 2019, from https://www.cio.com/article/3269030/artificial- 
intelligence/navigating-ai-strategy-in-your-industry.html

[10] New, J. (2018). Why the United States Needs a National Artificial Intelligence Strategy and What it Should Look Like. Center for Data Innovation, 65.

[11] ATKearney. (2018). How and When to Apply AI: The Case for Smart Adoption. Retrieved January 4, 2019, from http://www.atkearney.com/digitaltransformation/article?/a/how-and-when-to-apply-ai-thecase-for-smart-adoption

[12] Davis, J. (2018). Adopting a Strategy to Prepare for AI ServiceNow Workflow. Retrieved January 4, 2019, from https://www.servicenow.com/workflow/ai-strategy.html

[13] Reddy, R. (2017, September 20). Enterprise AI: The Adoption Strategy \& Practical Solutions. Retrieved January 4, 2019, from https://acuvate.com/blog/enterprise-ai-adoption-strategypractical-solutions/

[14] Newman, M. (2018, February 1). Make it happen Strategies for adopting AI technology. Retrieved January 4, 2019, from https://inform.tmforum.org/data-analyticsand-ai/2018/02/make-happen-strategies-adopting-aitechnology/

[15] RANSBOTHAM, S., GERBERT, P., REEVES, M., DAVID, K., \& SPIRA, M. (2018). Artificial Intelligence in Business Gets Real. Retrieved January 4, 2019, from https://sloanreview.mit.edu/projects/artificialintelligence-in-business-gets-real/

[16] Bughin, J. (2018). Wait-and-See Could Be a Costly AI Strategy. Retrieved January 5, 2019, from https://sloanreview.mit.edu/article/wait-and-see-couldbe-a-costly-ai-strategy/

[17] Mahidhar, V., \& Davenport, T. H. (2018, December 6). Why Companies That Wait to Adopt AI May Never Catch Up. Harvard Business Review. Retrieved from https://hbr.org/2018/12/why-companies-that-wait-toadopt-ai-may-never-catch-up

[18] Carbonell, J. R. (1970). AI in CAI: An artificialintelligence approach to computer-assisted instruction. IEEE transactions on man-machine systems, 11(4), 190-202.

[19] Harhoff, D., Heumann, S., Jentzsch, N., \& Lorenz, P. (2018). Outline for a German Strategy for Artificial Intelligence.

[20] Barnes, E. (2016). Advanced Artificial Intelligence: Policy and Strategy.

[21] Ivanov, S. H., \& Webster, C. (2017). Adoption of robots, artificial intelligence and service automation by travel, tourism and hospitality companies-a cost-benefit analysis. Artificial Intelligence and Service Automation by Travel, Tourism and Hospitality Companies-A CostBenefit Analysis.

[22] Rao, T. (2017). Factors critical to the organisational adoption of artificial intelligence: a South African perspective (Doctoral dissertation, University of Pretoria).

[23] O'reilly survey highlights artificial intelligence skills gap. (2018). Professional Services Close - Up, Retrieved from https://search-proquest-

com.spjain.idm.oclc.org/docview/2024376574?accountid
$=162730$

[24] Srivastava, S. K. (2018). ARTIFICIAL INTELLIGENCE: WAY FORWARD FOR INDIA.Journal of Information Systems and Technology Management : $\quad$ JISTEM, 15, 1-23 doi:http://dx.doi.org.spjain.idm.oclc.org/10.4301/S18071775201815004

[25] Kolbjørnsrud, V., Amico, R., \& Thomas, R. J. (2017). Partnering with AI: How organizations can win over skeptical managers. Strategy \& Leadership, 45(1), 37-43. Retrieved from https://search-proquestcom.spjain.idm.oclc.org/docview/1873678530?accountid $=162730$

[26] Davenport, T. H., \&Mahidhar, V. (2018). What's your cognitive strategy? MIT Sloan Management Review, 59(4), 19-23. Retrieved from https://searchproquest-

com.spjain.idm.oclc.org/docview/2057219779?accountid $=162730$

[27] Westerman, G. (2018). Your company doesn't need a digital strategy. MIT Sloan Management Review, 59(3), 1-5. Retrieved from https://search-proquestcom.spjain.idm.oclc.org/docview/2023985478?accountid $=162730$

[28] Benes, R. (2018). How Are Marketers Successfully Adopting Artificial Intelligence - eMarketer Trends, Forecasts \& Statistics. Retrieved February 10, 2019, from https://www.emarketer.com/content/successful-aiadoption-requires-clear-strategies

[29] Ghobakhloo, M., Hong, T. S., Sabouri, M. S., \& Zulkifli, N. (2012). Strategies for Successful Information Technology Adoption in Small and Medium-sized Enterprises. Information, 3(1), 36-67. https://doi.org/10.3390/info3010036

[30] Paredes, D. (2017). Despite the hype, AI adoption still in early stages. Retrieved November 27, 2018, from https://www.cio.co.nz/article/628668/despite-hype-aiadoption-still-early-stages/

[31] Balasubramaniam, S. (2018). Artificial Intelligence. DAWN: Journal for Contemporary Research in Management, 5(1), 12-18.

[32] Elliot, B., \& Andrews, W. (2017). A Framework for Applying AI in the Enterprise. Gartner, 38.

[33] Anshori, M. I., Salim, U., \&Armanu. (2013). Application of Technology Acceptance Model to Wi-Fi User at Economics and Business Faculty of Brawijaya University (Study on Stratum-1 Students). European Journal of Business and Management, 5(17), 57-65-65.

[34] Andrews, W. (2018). Craft an Artificial Intelligence Strategy: A Gartner Trend Insight Report. Retrieved November 28, 2018, from https://www.gartner.com/doc/3847266/craft-artificialintelligence-strategy-gartner

[35] Vance, A. (2018). How We Got Here. Bloomberg Businessweek, (4570), 64-67.

[36] Indian IT decision makers bullish on AI in BFSI sector: Report. (2018). FRPT- Software Snapshot, 37-37.

[37] Dobrescu, E. M., \&Dobrescu, E. M. (2017). The Future of the Artificial Intelligence in Economics and 
Management. Review of General Management, 26(2), $81-89$.

[38] Lai, P. (2017). THE LITERATURE REVIEW OF TECHNOLOGY ADOPTION MODELS AND THEORIES FOR THE NOVELTY TECHNOLOGY. Journal of Information Systems and Technology Management, 14(1). https://doi.org/10.4301/S180717752017000100002

[39] Skerrett, D. (2018, August 29). The State of Artificial Intelligence Around the Globe. Retrieved November 28, 2018 , from http://www.econtentmag.com/Articles/Editorial/MobileMoment/The-State-of-Artificial-Intelligence-Around-theGlobe-126115.htm
[40] Tsoukas and Knudsen (2003) The Oxford Handbook of Organization Theory: Meta-Theoretical Perspectives. Oxford: Oxford University Press.

[41] Dobrescu, E. M., \&Dobrescu, E. M. (2017). The Future of the Artificial Intelligence in Economics and Management. Review of General Management, 26(2), 81-89.

[42] Woodside, J. M., \& Jr, F. K. A. (2017). Blockchain Technology Adoption Status and Strategies. Journal of International Technology and Information Management, 26(2), 30 .

[43] Barnes, E. (2016). Advanced Artificial Intelligence: Policy and Strategy.

\section{APPENDIX}

\section{A. LIST OF THE ARTICLES REVIEWED (AT)}

\begin{tabular}{|c|c|c|c|}
\hline ID & Title & Year & Author(s) \\
\hline AT1 & 3 Ways to Create a Strategic Framework for AI Adoption & 2017 & Hossein \\
\hline AT2 & Navigating artificial intelligence strategy in your industry & 2018 & Evans \\
\hline AT3 & $\begin{array}{l}\text { Why the United States Needs a National Artificial Intelligence Strategy and What } \\
\text { It Should Look Like }\end{array}$ & 2018 & New \\
\hline AT4 & How and When to Apply AI: The Case for Smart Adoption & 2018 & ATKearney \\
\hline AT5 & Adopting a Strategy to Prepare for AI - ServiceNow Workflow & 2018 & Davis \\
\hline AT6 & Enterprise AI: The Adoption Strategy \& Practical Solutions & 2017 & Reddy \\
\hline AT7 & Make it happen - Strategies for adopting AI technology & 2018 & Newman \\
\hline AT8 & Artificial Intelligence in Business Gets Real & 2018 & $\begin{array}{l}\text { Ransbotham, } \\
\text { Gerbert, Reeves, } \\
\text { David, \&Spira }\end{array}$ \\
\hline AT9 & Why Companies That Wait to Adopt AI May Never Catch Up & 2018 & $\begin{array}{l}\text { Mahidhar, V., \& } \\
\text { Davenport, T. H }\end{array}$ \\
\hline AT10 & Outline for a German Strategy for Artificial Intelligence & 2018 & $\begin{array}{lr}\text { Harhoff, } & \text { D., } \\
\text { Heumann, } & \text { S., } \\
\text { Jentzsch, } & \text { N., } \\
\text { Lorenz, P. } & \\
\end{array}$ \\
\hline AT11 & Advanced Artificial Intelligence: Policy and Strategy & 2016 & Barnes, E \\
\hline AT12 & $\begin{array}{l}\text { Adoption of robots, artificial intelligence and service automation by travel, } \\
\text { tourism and hospitality companies-a cost-benefit analysis }\end{array}$ & 2017 & $\begin{array}{l}\text { Ivanov, S. H., \& } \\
\text { Webster, C. }\end{array}$ \\
\hline AT13 & $\begin{array}{l}\text { Factors critical to the organizational adoption of artificial intelligence: A South } \\
\text { African perspective. }\end{array}$ & 2017 & Rao, T \\
\hline AT14 & O'Reilly Survey Highlights Artificial Intelligence Skills Gap & 2018 & O'reilly \\
\hline AT15 & Artificial Intelligence: Way forward for India & 2018 & Srivastava \\
\hline AT16 & Partnering with AI: how organizations can win over skeptical managers & 2017 & $\begin{array}{ll}\text { Kolbjørnsrud, } & \text { V., } \\
\text { Amico, R., } & \text { \& } \\
\text { Thomas, R. J. } & \end{array}$ \\
\hline AT17 & What's Your Cognitive Strategy? & 2018 & $\begin{array}{l}\text { Davenport, T. H., } \\
\text { \&Mahidhar, V. }\end{array}$ \\
\hline AT18 & Your company Doesn't Need a Digital Strategy & 2018 & Westerman, G \\
\hline AT19 & How Are Marketers Successfully Adopting Artificial Intelligence & 2018 & Benes, R \\
\hline AT20 & The Transformative Business model & 2016 & Kavadia \\
\hline AT21 & How the U.S.-China Power Competition Is Shaping the Future of AI Ethics & 2018 & Keller \\
\hline AT22 & Building Ethics into Artificial Intelligence & 2018 & $\begin{array}{l}\text { Yu, H., Shen, Z., } \\
\text { Miao, C., Leung, C., } \\
\text { Lesser, V. R., \& } \\
\text { Yang, Q. }\end{array}$ \\
\hline AT23 & Why Ethics is a High Hurdle for AI & 2008 & Mcdermott \\
\hline AT24 & Ethics in Advanced Robotics & 2011 & Operto \\
\hline AT25 & $\begin{array}{l}\text { Designing, Implementing and Enforcing a Coherent System of Laws, Ethics and } \\
\text { Morals for Intelligent Machines (Including Humans) }\end{array}$ & 2015 & Waser \\
\hline AT26 & Robot ethics: Mapping the issues for a mechanized world & 2011 & $\begin{array}{l}\text { Lin, P., Abney, K., } \\
\text { \&Bekey, G. }\end{array}$ \\
\hline AT27 & Social Choice Ethics in Artificial Intelligence & 2017 & Baum \\
\hline AT28 & Why Teaching Ethics to AI Practitioners Is Important & 2017 & Goldsmith, J., \& \\
\hline
\end{tabular}




\begin{tabular}{|c|c|c|c|}
\hline & & & Burton \\
\hline AT29 & Ethics in artificial intelligence: introduction to the special issue & 2018 & Dignum \\
\hline AT30 & Designing and building artificial intelligence infrastructure & 2020 & Violino \\
\hline AT31 & $\begin{array}{l}\text { Data-intensive applications, challenges, techniques and technologies: A survey } \\
\text { on Big Data }\end{array}$ & 2014 & $\begin{array}{l}\text { Philip Chen, C. L., } \\
\text { \& Zhang }\end{array}$ \\
\hline AT32 & Cloud robotics: Current trends and possible use as a service & 2013 & $\begin{array}{l}\text { Lorencik, } \\
\text { \&Sincak }\end{array}$ \\
\hline AT33 & A Berkeley View of Systems Challenges for AI & 2017 & 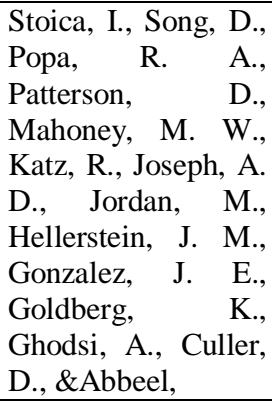 \\
\hline AT34 & Accountability of AI Under the Law: The Role of Explanation & 2017 & $\begin{array}{l}\text { Doshi-Velez, F., } \\
\text { Kortz, M., Budish, } \\
\text { R., Bavitz, C., } \\
\text { Gershman, } \\
\text { O'Brien, S., } \\
\text { Schieber, S., Waldo, } \\
\text { J., Weinberger, D., } \\
\text { \& Wood, A }\end{array}$ \\
\hline AT35 & Winning the war for AI talent & 2018 & Shein \\
\hline AT36 & UK must speed up and skill up to co-drive fourth industrial revolution & 2017 & McKenna \\
\hline AT37 & Towards Competence Development for Industry 4.0 & 2018 & $\begin{array}{l}\text { Kravcik, M., Wang, } \\
\text { X., Ullrich, C., } \\
\text { \&Igel, C }\end{array}$ \\
\hline
\end{tabular}

